\title{
LÍMITES DE RESPONSABILIDAD DE LAS CONVENCIONES INTERNACIONALES DE TRANSPORTE DE MERCANCÍAS Y POSIBILIDAD DE RECLAMACIÓN BAJO LOS SEGUROS DE TRANSPORTE*
}

\section{LIABILITY LIMITATIONS CONTAINED IN INTERNATIONAL CONVENTIONS REGARDING GOODS TRANSPORTATION AND THE CLAIMING POSSIBILITY UNDER TRANSPORTATION INSURANCE}

\author{
Luis Felipe García** \\ Martín Gutiérrez Sokoloff **** \\ Fecha de recepción: 1 de diciembre de 2016 \\ Fecha de Aceptación: 15 de diciembre de 2016 \\ Disponible en línea: 30 de diciembre de 2016
}

\section{Para Citar este articulo/ To cite this article}

García, Luis Felipe \& Gutiérrez Sokoloff, Martín, Limites de responsabilidad de las convenciones internacionales de transporte de mercancías y posibilidad de reclamación bajo los seguros de transporte, 45 RIS, 271-308 (2016). http://dx.doi.org/10.11144/ Javeriana.ris45.1rci

doi:10.11144/Javeriana.ris45.1rci

\footnotetext{
* Aparte del trabajo de grado para la obtención del título de especialistas en derecho de seguros de la Pontificia Universidad Javeriana.

** Abogado de la Universidad Pontificia Bolivariana, Especialista en Contratación Internacional de la Universidad Externado de Colombia. Director Jurídico de Panalpina para la Región Andina. E-mail 1felipegarcia86@hotmail.com

*** Abogado de la Pontificia Universidad Javeriana. Abogado de la Dirección Jurídica de la Pontificia Universidad Javeriana. E-mail: martingutierrezs@gmail.com
} 


\section{RESUMEN}

El presente trabajo busca establecer, a partir de un análisis de las decisiones jurisprudenciales en diferentes países, cuál es el manejo que se le dá en cada una de estas jurisdicciones a la aplicación de los límites de responsabilidad establecidos en convenciones internacionales o en normativa interna. Con esto se busca crear un panorama para las compañías de seguros que explotan el ramo de seguros de transporte respecto de la posibilidad de recuperación cuando ejercen una acción de subrogación en contra del transportador.

Palabras clave: Seguros de transporte; convenciones internacionales; Reglas de la Haya; Reglas de la Haya-Visby; COGSA; Convención de Montreal; Transporte aéreo; Transporte marítimo; Transporte terrestre 


\section{ABSTRACT}

This article pretends to establish, parting from an analysis from the courts rulings from different countries, how the liability limitations contained in international conventions or in the local law are applied in each jurisdiction. From this analysis, this article tries to create a panorama for insurance companies that exploit transportation insurance regarding the possibility to recuperate part of the indemnization when acting or pursuing against the transporter.

Key words: Transportation insurance; international conventions; Hague Rules; Hague-Visby Rules; COGSA; Montreal Convention; Aereal transportation; Terrestrial Transportation; Maritime Transportation

\section{SUMARIO}

1. INTRODUCCIÓN 2. ANÁLISIS DE JURISPRUDENCIA 2.1. Análisis de la Jurisprudencia en Francia 2.2. Análisis de la Jurisprudencia en Brasil 2.3. Análisis de la Jurisprudencia en Colombia 2.4. Análisis de la Jurisprudencia en Panamá 2.5. Análisis de la Jurisprudencia en Estados Unidos 2.6. Análisis de la Jurisprudencia en el Reino Unido 3. CONCLUSIONES 4. BIBLIOGRAFÍABIBLIOGRAFÍA 5. JURISPRUDENCIA 6. NORMATIVIDAD 


\section{INTRODUCCIÓN}

Dentro de los seguros de transporte, se pueden encontrar tanto seguros de responsabilidad civil, como seguros de daños. En el primer caso se hallan los seguros donde los mismos transportadores son tomadores y asegurados; en el segundo caso el tomador puede ser el transportador o el generador de carga, pero el asegurado será siempre el último sujeto en cuestión como el ente con un interés directo e inmediato sobre las mercancías transportadas.

Respecto de lo anterior, la Corte Suprema de Justicia en Sentencia 4799 de Septiembre 30 de 2002, Magistrado Ponente Carlos Ignacio Jaramillo $^{1}$, hace la siguiente disertación:

El transportador puede actuar como tomador en las siguientes circunstancias: a) Protegiendo su interés propio (por cuenta propia): Bajo este entendido se está frente a un seguro de responsabilidad civil en el cual el transportador es a su vez tomador y asegurado, pero no beneficiario. Protege su actividad de llevar una cosa de un lugar a otra en el estado que la recibió, ya que de no hacerlo esto afecta directamente su patrimonio, pues como se establece en el artículo 1127 del Código de Comercio, el asegurador tiene la obligación de “...indemnizar los perjuicios patrimoniales que cause el asegurado..." ${ }^{2}$; b) Para proteger interés ajeno (Por cuenta ajena), pues se aseguran las mercancías en caso de no llegar en buen estado a su destino final. En la práctica no se da este seguro muchas veces de esta manera, pues el interés del transportador no son las mercancías en sí mismas y; c) Para proteger ambos intereses. Esto es viable en Colombia, ya que se tiene una concepción amplia del seguro por cuenta ajena, tanto que si no se especifica nada, se cubre al tomador hasta el límite de su interés en el Contrato “ $y$, en lo demás, con la misma limitación, como estipulación en provecho de tercero"”.

Adicionalmente, sin ahondar en la legalidad o no de la siguiente práctica - ya que no es la finalidad del presente artículo - en el mercado es posible encontrar otro tipo de seguros en la relación que se da entre

1 Corte Suprema de Justicia. Sala de Casación Civil. Sentencia 4799 de Septiembre 30 de 2002. M.P. Carlos Ignacio Jaramillo Jaramillo.

2 Ibídem.

3 Ibídem. 
transportador y generador de carga. Esta práctica se resume en que las coberturas contratadas por los transportadores tienen ciertos límites determinados, sin embargo en ocasiones el valor de las mercancías supera tales demarcaciones y en tal sentido - con el fin de evitar responder con su propio patrimonio - los transportadores exigen a los generadores de carga pagar un seguro por la porción del valor de la carga que supera la suma asegurada, a lo cual se le conoce como "extensiones". En estos casos puntuales, puede ser el generador de las mercancías el tomador del seguro y el transportador quien funge como asegurado.

Por otro lado, los generadores de carga contratan por cuenta propia sus seguros de transporte típicamente de daños, pues estos cubren directamente las mercancías con base en su valor comercial e incluso se pueden encontrar coberturas adicionales que además de amparar el valor de los fletes y los bienes transportados, cubren elementos tales como el lucro cesante, impuestos y gastos adicionales (bodegajes, inspecciones, entre otros) derivados de un siniestro que afecte los productos.

Llevando todo lo expuesto a la esfera del transporte internacional de mercancías, se debe tener en cuenta que existen tratados internacionales que regulan cada medio - de transporte - y que limitan las indemnizaciones que se deben dar por siniestros sobre la carga con base en el peso de ésta o con base en las unidades (contenedores, pallets, cajas) trasladadas de un lugar a otro. Ahora, si se tiene en cuenta que generalmente los transportadores únicamente aseguran su responsabilidad legal o, que a falta de un seguro, sólo deben responder por los límites establecidos por las convenciones, pueden encontrarse incongruencias entre el valor que indemnice una aseguradora bajo una póliza de daños contratada por el generador de carga y los que se puede recuperar esta misma en una subrogación frente al transportador y/o frente a su aseguradora.

En desarrollo de lo expuesto, el siguiente artículo busca realizar un análisis jurisprudencial de decisiones arbitrales y sentencias aplicables con el fin de determinar que normas y de qué forma se están aplicando en los países con los que Colombia tiene un gran comercio internacional de transporte de mercancías. 


\section{ANÁLISIS DE JURISPRUDENCIA}

\subsection{Análisis de la Jurisprudencia en Francia}

En Francia, las cortes han analizado varios casos en los que se ha estudiado la limitación de la responsabilidad del transportador de acuerdo con lo establecido en las convenciones internacionales (Reglas de la Haya-Visby, Convención de Montreal y Convención CMR). En estas decisiones, se ha claramente establecido un respeto por los límites de responsabilidad contenidos en estos acuerdos internacionales.

Como ejemplo, la sentencia del 31 de mayo de 2001 de la Corte de Apelaciones de Versalles limitó la responsabilidad del transportador a los límites contenidos en las Reglas de la Haya-Visby. En el caso objeto de la decisión, fueron enviados desde Genneviliers (Francia) hasta Osaka, acondicionados en 3 pallets, 45 cartones. Hecha la verificación por el destinatario en Osaka, se encontró que sólo habían llegado 25 de los 45 cartones, razón por la cual fue indemnizado el destinatario por sus aseguradores. E1 2 de febrero de 1993, los aseguradores interponen una acción en contra del transportador (MAZINTER), quien a su vez llama en garantía a KERTENAIRE, CLEVE EN ZONEN (quien a su vez solicitó la garantía de KERTENAIRE y P\&O CONTAINER EUROPE BV).

La decisión tomada por la corte es condenar al transportador y a KERTENAIRE por el valor de 13.333,40 Derechos Especiales de Giro (de ahora en adelante DEG) de acuerdo con la limitación de 666,67 DEG por cada paquete (entendiéndose individualizados los 20 paquetes que se perdieron en el transporte y no sobre los 3 palets $)^{4}$.

En otras sentencias de la Corte de Casación, también se ha establecido que la responsabilidad tiene como techo (plafond), el límite contenido en las convenciones internacionales ${ }^{5}$.

Ahora bien, estos límites no son absolutos, como varias decisiones

4 Cour d'Appel de Versailles, 12ème chambre section 2 D.C./P.G. ARRET N ${ }^{\circ}$ DU 31 mai 2001 R.G. N ${ }^{\circ}$ 98/04056: Obtenida el 7 de mayo de https://www.legifrance.gouv.fr/affichJuriJudi.do?oldAction=rec hJuriJudi\&idTexte=JURITEXT000006938230\& fastReqId=813842198\&fastPos $=2$.

5 Court de Cassation, chambre commerciale. $\mathrm{N}^{\circ}$ de pourvoi: 14-24912. Obtenida el 13 de mayo de 2016 de: https://www.legifrance.gouv.fr/affichJuriJudi.do?oldAction=rechJuriJudi\&idTexte=JURIT EXT000032159282\&fastReqId=353743664\&fastPos=30; 
lo han contemplado. Como se demostró con la jurisprudencia anterior, los límites son respetados salvo que los daños tengan como origen o se deban por dolo o culpa grave ("fautes lourdes").

El primero de los casos, fallado el 30 de marzo del 2000, la compañía francesa SIL-EX vendió al Ministerio de Agricultura de Egipto una serie de equipos para la instalación in-situ de tres estaciones de semillas con sus respectivos silos. Con el fin de trasladar los equipos de Francia a Egipto, SIL-EX se acercó al comisionista de transporte SAGA FRANCE, quien se encargó de los trayectos marítimos del transporte, entre Rouen y Alejandría. En uno de los viajes, elementos que componían un puente báscula que iban a bordo del barco Tatarbunary cayeron por la borda; otros materiales que iban en contenedores de tipo Open Top y elementos metálicos fueron dañados.

La compañía Assurances Generales de France, desembolsó a SIL-EX las siguientes sumas como indemnización por los daños sufridos: 199.236 Francos por los elementos del puente bascula y 336.757 Francos por los otros equipos y elementos dañados.

En el estudio del presente caso, la primera instancia, decidida por el Tribunal de Comercio de Nanterre, estableció que SAGA FRANCE y COMPAGNIE MORBIHANNAISE ET NANTAISE DE NAVIGATION (C.M.N.N) quien era el transportador marítimo, sólo estaban obligadas a pagar las sumas que no superaran el límite establecido, de 2 DEG por kilo de acuerdo con las Reglas de la Haya-Visby. La aseguradora interpuso un recurso de apelación, porque esta decisión del Tribunal de Comercio de Nanterres va en contra de la excepción contenida en el artículo 4.5 literal e de la convención, respecto de la inaplicación de la limitación de responsabilidad en ciertos casos específicos.

En el análisis de segunda instancia del presente caso (sentencia del 30 de marzo del 2000), la Corte de Apelaciones de Versalles no aplica los límites de responsabilidad del transportador marítimo y de su comisionista de transporte, por cuanto cometieron una falta grave por haber transportado una mercancía sin tener en cuenta las recomendaciones expresas del cargador de tener cuidado con la mercancía, debiendo, por lo tanto, pagar la totalidad de la indemnización desembolsada por la aseguradora en favor del asegurado: 
“(....)Que se deriva de lo anterior que ni el transportador maritimo ni su comisionista de transporte, que es el garante de este último, no pueden prevalerse de una limitación de responsabilidad, menos cuando el comisionista de transporte cometió una falta personal por aceptar este tipo de cargamento cuando se le había pedido expresamente que tuviera cuidado con la carga objeto del contrato de transporte. Que, por lo anterior, el juzgamiento deferido será revocado y las sociedades SAGA FRANCE y C.M.N.N serán condenadas a pagar de manera solidaria a la compañia AGF la suma de 199.236 francos, cubriendo la perdida de los largueros con los intereses legales que haya lugar desde la aceptación de la demanda, incluyendo las respectivas demoras; b) sobre las reclamaciones concerniendo los materiales posicionados en los contenedores "Open Top", considerando que estos contenedores fueron de igual forma posicionados sobre la cubierta, contrario a las instrucciones formales dadas al comisionista de transporte y sin la autorización expresa del cargador; que por los mismos motivos dados en el punto anterior, este posicionamiento de la carga es imputable a la falta del comisionista de transporte como a la compañia de transporte marítimo; que la falta cometida debe ser calificada como inexcusable en la medida que estos contenedores de lona no pueden soportar sin daño una larga travesía en periodo invernal, no mojarse como previsiblemente podía pasar así como a los efectos de los violentos vientos; que el descuido y la inaptitud tanto del transportador maritimo como del comisionista de transporte, se encuentran, de esta forma, suficientemente establecidas..." 6

En el segundo caso, se analizó por la Corte de Apelación de Aix-enProvence unos daños causados a un camión y su remolque y a un cargamento de madera transportado desde Francia a Algeria. Se determinó que los daños causados a los elementos, en su transporte, se debieron a la comisión de una falta grave, véase una actitud temeraria, en el transporte de la mercancía, imposibilitando la aplicación de los límites contenidos en la Convención de Bruselas:

“Atendiendo que la Compagnie Nationale Algérienne de Navigation no está en derecho a hacer prevalecer las limitaciones de responsabilidad instauradas por el artículo 4 numeral 5 literal a de la Convención de Bruselas del 25 de agosto de 1924, emendada desde ese momento. Que el daño resulta de un acto o una omisión de la Compagnie Nationale Algérienne de Navigation que por demás fue temerario y con conciencia que podía probablemente generar un daño; que la Compagnie Nationale Algérienne de Navigation cometió una falta inexcusable..."

6 Cour d'appel de Versailles, du 30 mars 2000, N de RG: 1997-3796 Obtenida el 6 de mayo de 2016 de https://www.legifrance.gouv.fr/affichJuriJudi.do?oldAction=rechJuriJudi\&idTexte=JURITEXT00 0006936432\&fastReqId=4046634\&fastPos=29. Traducción libre de los autores.

7 Cour d'appel d'Aix-en-Provence, 2ème Chambre ARRÊT AU FOND DU 3 JUILLET 2008 No 2008/ $280 \mathrm{~N}^{\circ}$ de RG: 07/09200. Obtenida el 7 de junio de 2016 de: https://www.legifrance.gouv.fr/ affichJuriJudi.do?oldAction=rechJuriJudi\&idTexte=JURITEXT000019605185\& fastReqId=2078805 241\&fastPos=6. Traducción libre de los autores. 
En la sentencia del 2 de octubre de 2003, se estableció por la Corte de Apelación de Versalles que, aplicando el artículo 29 de la Convención $\mathrm{CMR}^{8}$ y demostrándose la falta grave imputable al transportador, esto lo priva del beneficio de la limitación de responsabilidad y de la indemnización establecida en el artículo 23 de la misma convención?

"Considerando que el juzgamiento apelado debe ser confirmado en el sentido que el artículo 29 de la Convención CMR establece que la culpa grave imputable a la sociedad Y... FRANCE la priva del beneficio de la limitación de la responsabilidad y de la indemnización establecida por el artículo 23 de esta convención, que por lo tanto la condena impuesta en contra de esta sociedad y en favor de las aseguradoras por la suma de: $790.309 \mathrm{~F}(120.481,34$ )$+290.204,13 F(44.241,33)=1.080 .513,13 \mathrm{~F}$ de los cuales $164.723,16$ aumentados conforme al artículo 27 de la mencionada convención, de intereses a la tasa del 5\% contados desde el 21 de octubre de 1998 fecha del recibo de la subrogación" ${ }^{10}$

Los anteriores casos analizados por las Cortes de Apelación de Versalles y Aix-en-Provence, son una muestra de las decisiones jurisprudenciales que claramente respetan los límites establecidos por las convenciones internacionales, salvo para los casos en que se haya presentado una culpa grave por parte del transportador y/o del comisionista de transporte porque las mismas convenciones contienen la inaplicación de los límites como el artículo 29 de la Convención $\mathrm{CMR}^{11}$, el literal e) del artículo

8 Artículo 29. Convención Relativa al Contrato de Transporte Internacional de Mercaderías por Carretera (CMR). Entrada en vigencia el 2 de julio de 1961. Obtenida el 23 de mayo de 2016 de: http://www.unece.org/fileadmin/DAM/trans/conventn/cmr_e.pdf

9 Aunque Colombia no es un país que haga parte de esta convención, como tampoco lo son los países del continente americano, es importante esta decisión porque demuestra claramente que, para las cortes francesas, los límites se respetan siempre y cuando no haya una culpa grave. Presentándose una culpa grave, el causante del daño no puede valerse de las limitaciones de la responsabilidad establecidas en las diferentes convenciones.

10 Cour d'appel de Versailles, 12ème chambre section 2 J.F.F. ARRET DU 02 Octobre 2003 R.G. N. 01/07128: obtenida el 5 de mayo de 2016 de

https://www.legifrance.gouv.fr/affichJuriJudi.do?oldAction=rechJuriJudi\&idTexte=JURITEXT0000 06943374\& fastReqId $=1011430227 \&$ fastPos $=1$. Traducción libre de los autores.

11 Art. 29 Convención CMR: The carrier shall not be entitled to avail himself of the provisions of this chapter which exclude or limit his liability or which shift the burden of proof if the damage was caused by his wilful misconduct or by such default on his part as, in accordance with the law of the court or tribunal seized of the case, is considered as equivalent to wilful misconduct. 2. The same provision shall apply if the wilful misconduct or default is committed by the agents or servants of the carrier or by any other persons of whose services he makes use for the performance of the carriage, when such agents, servants or other persons are acting within the scope of their employment. Furthermore, in such a case such agents, servants or other persons shall not be entitled to avail themselves, with regard to their personal liability, of the provisions of this chapter referred to in paragraph 1. 


\section{$4^{12}$ o el numeral 4 del artículo 4 bis ${ }^{13}$ de las Reglas de la Haya-Visby cuando haya una culpa grave o dolo.}

\section{Las cortes francesas consideran superiores las normas contenidas en las convenciones que las normas nacionales tales como el Código Civil. Como ejemplo de esto, se puede analizar la sentencia de la Corte de Casación del 30 de junio de 2015 donde estableció lo siguiente:}

“... que en el transporte de mercaderías, la responsabilidad del transportador, en caso de destrucción, perdida, avería o de retardo, está limitada a la suma de diecisiete derechos especiales de giro por kilogramo, salvo declaración especial hecha por el cargador; que esta limitación es absoluta (...)que condenando a la sociedad Air France solidariamente con las sociedades Geodis y Helvetia a pagar a la sociedad Biomérieux la suma de 42 945,50 euros y la misma suma para los aseguradores de esta, dentro de los límites del valor correspondiente en euros de 3 469,40 derechos especiales de giros (DEG) y condenándola a garantizar a las sociedades Géodis y Helvetia por el monto total de 42 845,50 euros dentro del mismo límite, la corte de apelaciones no dictó una condenación del transportador aéreo excediendo el límite de indemnización establecido por la Convención de Montreal (...)

Atendiendo que la sociedad Biomérieux y sus aseguradores apelaron la aplicación del límite de responsabilidad de acuerdo con la Convención de Montreal y que en su recurso establecieron que la aplicación del artículo 22 de la Convención no excluye la aplicación del artículo 1150 del Código Civil; que el principio según el cual el dolo escapa a todas las reglas en la medida que no le aplican las clausulas limitativas de la responsabilidad sean estas de origen contractual o legal, por ser de orden público y se le impone al juez la aplicación de esta norma; que enunciando la gravedad de la falta cometida por el transportador aéreo, esta no tiene incidencia sobre la indemnización cuando este transporte está regulado por la Convención de Montréal porque no quita la limitación de la responsabilidad en caso de falta inexcusable, por lo que la corte de apelación violó el artículo 1150 del código civil; Atendiendo que el artículo 22 de la Convención de Montreal establece que el acto u omisión del transportador aéreo hecho con la intención de provocar daño o de manera temeraria y teniendo consciencia que un daño resultaría probablemente no tiene por efecto de excluir la aplicación de los límites de indemnización previstos por ese texto para la reparación de los daños por las mercancías trasportadas por vía aérea. Que la corte de apelación dedujo que el

12 Art. 4 Lit. e) Reglas de la Haya Visby: (e) Neither the carrier nor the ship shall be entitled to the benefit of the limitation of liability provided for in this paragraph if it is proved that the damage resulted from an act or omission of the carrier done with intent to cause damage, or recklessly and with knowledge that damage would probably result.

13 Art. 4 Num. 4 Reglas de la Haya Visby: 4. Nevertheless, a servant or agent of the carrier shall not be entitled to avail himself of the provisions of this article, if it is proved that the damage resulted from an act or omission of the servant or agent done with intent to cause damage or recklessly and with knowledge that damage would probably result. 
dolo o la falta inexcusable del transportador aéreo de mercaderías no permite que este asuma a su cargo la reparación integral del prejuicio; que el motivo no está fundado. Por estos motivos: Rechaza los motivos de la apelación;"'14

Se revisó en este fallo la aplicación de una norma de orden público contenida en el artículo 1150 del Código Civil en el caso de la comisión de un daño con dolo por parte del transportador. De haberse aplicado la norma de orden público, se hubiera tenido que indemnizar al cargador la totalidad del valor de las mercancías. Sin embargo, en el análisis del recurso de casación contra la sentencia de la Corte de Apelación, la Corte de Casación estableció la preferencia de la aplicación de la Convención de Montreal sobre una norma interna de orden público, en especial el artículo 22 de la Convención sobre el artículo 1150 del Código Civil. De acuerdo con esto, la limitación contenida en la convención para la indemnización sigue en pie.

El anterior análisis nos demuestra que las cortes en Francia se apegan estrictamente a lo contenido en las convenciones ya sea para la aplicación de los límites como para su inaplicación por una falta grave. Se le da una preferencia a estos acuerdos internacionales sobre el derecho interno, por más que las normas en el derecho interno prohíban cualquier pacto en contrario.

\subsection{Análisis de la Jurisprudencia en Brasil}

Al revisar la jurisprudencia de este país, se encuentra que difícilmente pueden llegar a aplicar los límites de responsabilidad establecidos en los tratados internacionales cuando los asuntos se ventilan en cortes o tribunales locales.

Por ejemplo en la Sentencia No. 2016.0000053634 de Enero de 2016, cuyo relator es el Magistrado Edson Luiz De Queiroz, el Tribunal de Justicia del Estado de Sao Paulo establece lo siguiente:

"La relación jurídica que existe entre las partes no se rige por las disposiciones del Código de Defensa del Consumidor, ya que no se presentan las figuras de

14 Cour de cassation, chambre commerciale, Audience publique du mardi 30 juin 2015 , $\mathrm{N}^{\circ}$ de pourvoi: 13-28846. Obtenido el 10 de junio de 2016 de: https://www.legifrance.gouv.fr/affichJuriJudi.do?o 1dAction=rechJuriJudi\&idTexte $=$ JURITEXT000030841606\&fastReqId $=963513812 \&$ fastPos $=11$. Traducciòn libre de los autores 
consumidor y proveedor. La aseguradora no es el adquirente final, aunque se subrogue en los derechos del asegurado." 15

Seguidamente la misma Sentencia indica:

"Pues bien, no se aplica la hipótesis de indemnización limitada prevista en la Convención de Montreal o en el Código Brasilero de Aeronáutica, pues esta limitación está restringida a los casos de daños procedentes de accidente aéreo, cuando no es posible evaluar el valor de la carga transportada." 16

Finalmente la mencionada Sentencia concluye diciendo que:

"En los casos de extravio o hurto de las mercancías transportadas, sin embargo, la reparación del daño se debe a una falla en el servicio, la cual es regulada por el derecho común. En esas condiciones el reembolso debe ser integral, correspondiendo al valor de la indemnización pagada. "17

En suma, el Tribunal descarta la aplicación de los límites de responsabilidad no porque se trate de una relación de consumo, sino porque según el entendimiento de ellos, dichos raseros se aplican exclusivamente cuando se trata de accidentes aéreos, los cuales circunscriben únicamente a eventos súbitos e imprevistos que ocurran en operaciones de embarque, desembarque o mientras la carga se encuentre dentro de la aeronave.

De tal manera, otro tipo de eventos como hurto o extravío, los cuales derivan de un mal servicio por parte de la aerolínea, quedan excluidos de la aplicación de los límites de responsabilidad.

Con base en lo anterior, se concluye que se desconoce totalmente lo establecido en el numeral 3 del Artículo 18 de la Convención de Montreal, según el cual el transporte aéreo es el período durante el cual la carga se encuentra bajo custodia del transportador, amparando incluso a los agentes de la Aerolínea, tal como se indica en el numeral 1 del Artículo 30 del tratado en cuestión:

"1. Si se inicia una acción contra un dependiente del transportista, por daños a que se refiere el presente Convenio, dicho dependiente o agente, si prueban que actuaban en el ejercicio de sus funciones, podrán ampararse e $n$ las condiciones

15 Tribunal de Justicia de Sao Paulo. Sentencia No. 2016.0000053634 de Enero de 2016. M.P. Edson Luiz de Queiroz. Traducción libre de los autores.

16 Ibídem

17 Ibìdem 
y los límites de responsabilidad que puede invocar el transportista en virtud del presente convenio." 18

No obstante lo indicado por la anterior sentencia, según la cual no hay relación de consumo por no ser la aseguradora el consumidor final, en la Sentencia No. 2015.0000901228 del mismo Tribunal, cuyo relator es el Magistrado Marino Neto, se asume una tesis totalmente contraria al indicar lo siguiente:

"Para el cálculo de la responsabilidad del transportador aéreo por la pérdida de la carga, aplican las disposiciones del Código de Defensa del Consumidor, cuando el evento haya ocurrido durante la vigencia de esta norma, alejándose así de la indemnización con base en límites de responsabilidad."

Más adelante, la decisión del Tribunal indica que la compensación por parte de la aerolínea a la aseguradora debe ser plena, ya que de acuerdo con lo establecido por el Supremo Tribunal Federal, la aseguradora tiene acción de subrogación frente a quien haya causado el daño con base en el límite establecido en el contrato de seguro:

“El asegurador tiene acción regresiva (subrogación) contra quien ocasionó el daño por el valor que definitivamente haya pagado, hasta el límite previsto en el contrato de seguro " 20 .

No obstante lo anteriormente relatado, el desconocimiento de los límites de responsabilidad parece presentarse en instancias locales, pues al revisar la jurisprudencia del Supremo Tribunal de Justicia, se pueden observar decisiones apartadas de lo antes visto.

Tal como se indica en la decisión del Recurso Especial No 1.076.465 SP (2008/0160567-4) del Supremo Tribunal de Justicia, Relator Ministro Marco Buzzi, los límites de responsabilidad establecidos en el transporte marítimo son plenamente admisibles:

"En los términos de la jurisprudencia establecida en la Segunda Sección, se considera válida la cláusula del contrato de transporte marítimo que estipula un límite máximo de indemnización en caso de daño de la carga transportada cuando

18 Art. 30 Num. 1. Convenio para la unificación de ciertas reglas para el transporte aéreo internacional, hecho en Montreal el 28 de mayo de 1999.

19 Tribunal de Justicia de Sao Paulo. Sentencia No. 2015.0000901228. M.P. Marino Neto. Traducciòn libre de los autores.

20 Tribunal de Justicia de Sao Paulo. Sentencia No. 2015.0000901228. M.P. Marino Neto. Traducciòn libre de los autores 
haya una igualdad evidente de los sujetos integrantes de la relación jurídica, cuya libertad contractual se revela ampliamente, no aplicando, por lo tanto, la hipótesis del Artículo 6 Inciso VI del Código de Defensa del Consumidor según la cual se establece el principio de reparación integral de los daños. "21

En el mismo sentido de la decisión antes transcrita, respecto del modo aéreo se pronuncia el Supremo Tribunal de Justicia, en la cual el relator Ministro Luis Felipe Salomão expresa lo siguiente en la Decisión del Recurso Especial No 1.162.649 - SP (2009/0209202-1):

"Descartando el Código de Defensa del Consumidor en el caso concreto, aplica la Convención de Varsovia y normas complementarias respecto del transporte aéreo internacional, los cuales imponen una indemnización limitada equivalente a 17 derechos especiales de giro, para efectos de reparar los daños causados a la mercadería." 22

Si bien como se indicaba anteriormente, las decisiones del Supremo Tribunal de Justicia de Brasil contemplan la aplicabilidad de los límites de responsabilidad, el tema no es totalmente pacífico, pues para la decisión antes citada, se plantean dos salvamentos de voto. En estos se indica que sí se debe aplicar el Código de Defensa del Consumidor, debido a que la aseguradora se subroga en los derechos del asegurado y este último sí es el consumidor final, por lo cual debe darse una indemnización plena de perjuicios, siguiendo lo establecido por las decisiones anteriormente citadas del Tribunal de Justicia de Sao Paulo.

Con base en lo expuesto respecto de la aplicabilidad de los límites de responsabilidad en Brasil, puede concluirse entonces que no hay una total certeza de la aplicación de los mismos, pudiendo presentarse decisiones contrarias dependiendo del tribunal o magistrado que las revise.

\subsection{Análisis de la Jurisprudencia en Colombia}

En términos generales, para los casos de transporte aéreo y terrestre, en Colombia es clara la aplicación de los límites de responsabilidad

21 Supremo Tribunal de Justicia. Recurso Especial No 1.076.465 - SP (2008/0160567-4) del 09.11.1994, Relator Ministro Marco Buzzi; En concordancia con lo anterior: Supremo Tribunal de Justicia. Recurso Especial 39.082/SP. Relator Ministro Nilson Naves; Supremo Tribunal de Justicia. Rel. p/ Acórdão Ministro Fontes de Alencar, Segunda Seção, julgado em 09.11.1994, DJ 20.03.1995. Traducción libre de los autores.

22 Supremo Tribunal de Justicia. Recurso Especial No 1.162.649 - SP (2009/0209202-1). Relator Ministro Luis Felipe Salomão. Traducción libre de los autores. 
contenidos en las normas aplicables. No obstante lo anterior, en lo que respecta el transporte marítimo, se presenta un claro inconveniente en Colombia al no haberse adoptado ningún tratado internacional que regulan la materia en cuestión, por lo cual el transporte marítimo se convierte en una clara excepción a la afirmación hecha al respeto de los límites de responsabilidad.

No en vano, en una de las pocas sentencias sobre el tema de indemnizaciones en el transporte marítimo que han llegado a manos de la Corte Suprema de Justicia se suscitan controversias que tal vez en otro modo de transporte no tendrían el mismo problema por existir normas claras que lo regulan. En la Sentencia del 8 de septiembre de 2011 de la Corte Suprema de Justicia, cuyo Magistrado Ponente es William Namén Vargas, hay dos puntos centrales de controversia:

En primer lugar, la aseguradora como parte activa indica que no es viable aplicar ninguno de los tratados internacionales sobre la materia, ya que Colombia no ha acogido ninguno y que además el Artículo 1031 del Código de Comercio es claro al indicar que sobre los parámetros allí establecidos para las indemnizaciones por afectaciones a la carga, no es viable pactar algo en contrario. Adicionalmente argumenta que el Artículo 1031 es norma posterior a la que genera la contradicción (la cual se verá adelante) y por ende la más reciente debe prevalecer.

Por su parte, el transportador marítimo indica que lo establecido en el mencionado Artículo 1031 es de carácter general y que por ende prima la especialidad de lo establecido en el Artículo 1644, el cual abre la posibilidad para que se pacten límites a la responsabilidad del transportador.

“ARTÍCULO 1644. INDETERMINACIÓN DEL VALOR DE LAS MERCANCÍAS EN LA DECLARACIÓN - RESPONSABILIDAD. Cuando en la declaración inserta en el conocimiento no haya determinado el cargador el valor de las mercaderías pero sí su naturaleza, y el transportador, su agente maritimo o el capitán del buque no hubieren formulado la oportuna reserva sobre dicha declaración, se atendrá el transportador para la indemnización al precio de dichas mercaderías en el puerto de embarque. Pero en este caso podrá pactar un límite máximo a su responsabilidad. "'23 (Subrayado fuera del texto original).

23 Código de Comercio Colombiano (CC0). Decreto 410 de 1971. Art. 1644. 
Por otro lado, se discute si de acuerdo con lo indicado en el primer inciso del Artículo 1644 del Código de Comercio antes citado el valor de las mercancías estaba declarado o no dentro del conocimiento de embarque.

De acuerdo con lo que alega la aseguradora, la factura de las mercancías transportadas es mencionada en la casilla 6 del conocimiento de embarque y además se indica el monto de los bienes, por lo cual se entendería que hubo declaración de valor, con lo cual no habría lugar a aplicar las limitaciones de responsabilidad establecidas en los tratados.

En contraposición al anterior argumento, se establece que existe un espacio dentro del conocimiento de embarque (Casilla 25) en el cual se debe incluir la declaración del valor de las mercancías. Si el monto de estas no se establece en el documento de transporte sino en un documento aparte como es la factura, entonces no hay lugar a que esta situación se tenga en cuenta para abrir la responsabilidad del transportador más allá de lo expresado en los tratados internacionales como limitante de responsabilidad.

En relación con la primera controversia, la Corte da prevalencia al criterio de especialidad de las normas sobre transporte bajo conocimiento de embarque y en ese sentido textualmente expresa que:

“..., el contrato de transporte marítimo de mercancías tiene regulación normativa, prevalente y de aplicación preferente a las normas del transporte en general (arts. 985 a 1035, C. de Co.), las cuales "aplicarán al transporte cualquiera que sea el medio empleado para realizarlo, sin perjuicio de normas contenidas en disposiciones especiales" (artículo 999, C. de Co.), o sea, aplican única y exclusivamente cuando las especiales no regulen la materia especifica, o por remisión expresa, por ejemplo, emitido conocimiento de embarque único o directo, la responsabilidad del transportador maritimo se rige por los artículos 986 y 987 del Código de Comercio (artículo 1646, C. de Co.). Por esto, el artículo 999 del Código de Comercio, descarta la aparente antinomia, al disponer la preeminencia de las normas especiales del transporte marítimo y la aplicación de las generales del transporte, en presencia de vacios o, desde luego, por expresa remisión." 24

24 Corte Suprema de Justicia, Sala de Casación Civil. Sentencia del 8 de septiembre de 2011. M.P. William Namen Vargas. 
En congruencia con el aparte antes citado, la Corte continúa con lo siguiente:

"Empero, perspectiva tan general del artículo 1644 es inexacta. La disposición por la cual el transportador "podrá pactar un límite máximo a su responsabilidad", es un permiso, y nada más que eso. Ella no contiene, ni siquiera remotamente, una reglamentación completa o exhaustiva de los términos a los cuales deben ceñirse tales convenciones. ${ }^{25}$

No obstante lo anterior, la Corte advierte que del sentido literal del Artículo 1644, podría inferirse que las partes en el contrato de transporte marítimo podrían limitar su responsabilidad, incluso hasta el punto de eludirla y en tal sentido concluye que “...si bien, en ejercicio de la autonomía privada, las partes están facultadas por el ordenamiento jurídico para establecer límites a su responsabilidad negocial o debitoria, y más concretamente, por un riesgo propio del negocio, tal facultad no es absoluta, sino sujeta a límites de orden público. "26

En este sentido, con el fin de evitar que las partes establezcan límites irrisorios y teniendo en cuenta que el Artículo 1644 no plantea un régimen propio de responsabilidad, lo que corresponde en este caso es integrar la norma local con otras normas específicas de carácter internacional que han regulado la materia a profundidad.

Con base en lo expuesto, si bien en Colombia no se ha acogido ningún tratado internacional en lo relativo al transporte de mercancía por vía marítima, con lo indicado en la Sentencia en cuestión, claramente se abre la puerta para que sean aplicable disposiciones de convenios en lo referente al menos a la limitación de responsabilidad.

En relación con el segundo elemento de análisis dentro de la Sentencia, según el cual hay controversia respecto de la declaración o no del valor de las mercancías dentro del conocimiento de embarque, la Corte concluye que es claro que el documento de transporte es diferente y soporta un contrato aparte del que soporta la factura de compraventa.

No obstante lo anterior, respecto de la exigencia de declarar el valor en el conocimiento de embarque para que no operen los límites de

25 Ibidem.

26 Ibidem. 
responsabilidad de un tratado determinado, se señala en la Sentencia que "Dicha exigencia, tiene su premisa en la consideración elemental conforme a la cual el valor de las mercaderías sea conocido por el transportador, y este conocimiento e inserción para la Sala, se cumple, y a con la expresión literal del valor, ora con la mención en su texto de un documento que la contenga, que desde luego, por razones lógicas ineludibles se inserta e integra su contenido. "27

Adicionalmente a lo anterior, la Corte va aún más lejos al indicar que “...el significado prístino de la locución declaración que, igualmente puede ser "tácita", por acto, hecho, conducta o comportamiento que impone una conclusión única, coherente, univoca e inequivoca, ya por inferencia lógica compatible o deducción incompatible con un sentido o dirección distinta... ${ }^{28}$.

Con base en lo anterior, en la Sentencia se concluye que "En el asunto litigioso, el marco fáctico concreto de circunstancias impone la conclusión clara, expresa, e inequivoca que el valor de las mercancías consta en la declaración inserta en el conocimiento de embarque, porque no otra explicación tiene la mención de los documentos que lo refieren. "29

En cuanto a la decisión y argumentación de la Corte sobre el segundo asunto litigioso, se destaca entonces que se basa primordialmente en que el transportador conozca el valor de lo que esté moviendo de un lugar a otro, ya sea por una declaración expresa o por una declaración tácita.

Con dicho argumento, se podría concluir entonces que es imposible que exista una limitación de responsabilidad para el transporte marítimo de mercancías en Colombia y la argumentación que hace la Corte del primer asunto litigioso se convierte en un esfuerzo totalmente inocuo por las siguientes razones:

Simplemente haciendo un barrido de conocimientos de embarque, se encuentra que en una cantidad considerable se menciona el número de la factura comercial, por lo cual según el concepto de la corte, hay un valor declarado.

Al consultar con diferentes empresas que se dedican al transporte de mercancías sobre este tema, ellos indican que indefectiblemente

\footnotetext{
27 Ibídem.

28 Ibídem.

29 Ibídem.
} 
es necesario para el transportador conocer la factura comercial de la mercancía que estén movilizando, ya que por ejemplo, tratándose de mercancías peligrosas, armas, medicinas para consumo humano, entre otras, se deben llevar a cabo unos procedimientos específicos para evitar siniestros o simplemente porque las aduanas en los diferentes destinos tienen exigencias específicas diferentes.

Con base en lo anterior, el número de factura se relaciona en el conocimiento de embarque para de tal manera relacionarlo con una operación específica, pero de ninguna manera es intención ni siquiera del embarcador hacer una declaración del valor.

Hay algunos casos de conocimientos de embarque máster donde no se relaciona el número de la factura, sin embargo siempre tendrán que hacer relación a un conocimiento de embarque hijo, en el cual siempre se va a hacer referencia al número de factura por lo explicado anteriormente.

Las navieras incluyen este tipo de información únicamente por solicitud de su cliente, pero no quiere decir que se acepte como una declaración de valor, pues las navieras que generalmente no son Colombianas, se rigen por Convenios Internacionales, según los cuales para que haya una declaración de valor debe indicarse claramente en el conocimiento de embarque, contrario a lo que indica la Corte, según la cual la declaración puede ser tácita o hacerse simplemente por referencia a otro documento.

No sólo dependiendo del tipo de mercancía se debe indicar el número de factura en el conocimiento de embarque. También se hace referencia a ésta debido a que allí se señalan cantidades y peso, información que necesariamente debe introducirse en el documento de transporte.

Si bien esta información puede encontrarse en una lista de empaque, este documento siempre hace referencia a la factura que lo ampara, por lo cual según el concepto de la Corte también se hablaría de un valor declarado.

En las exportaciones que salen desde Colombia es obligatorio para la naviera conocer la solicitud de autorización de embarque (SAE), el cual constituye un requisito aduanero y se materializa en un formulario de la DIAN con número 602. 
En las casillas 106, 107 y 113 del mencionado formulario se indican respectivamente el tipo de documento que soporta la operación de comercio exterior (generalmente factura), el número de este documento y el valor.

En conclusión, al resolver el primer asunto litigioso, la Corte abre la puerta para que Colombia, a pesar de no haber adoptado tratados internacionales en materia de transporte marítimo, puedan establecerse límites de responsabilidad, pero al decidir el segundo punto en conflicto retrocede en lo que había dicho anteriormente, pues de nada sirve decir que se puede limitar la responsabilidad si por falta de investigación de lo que ocurre en la práctica, bajo los argumentos expuestos en la Sentencia, esto se hace prácticamente imposible.

En transporte marítimo, al igual que acontece en Brasil y como se mencionó anteriormente, hay sentencias contrarias respecto de la aplicabilidad de los límites de responsabilidad del transportador y sobre cuál sería el límite. A parte del anterior fallo analizado, existe otro de la Corte Suprema de Justicia que analiza los límites de responsabilidad, estableciendo que los mismos pueden ser pactados aun así por debajo de los límites de las convenciones internacionales, de acuerdo con lo establecido por el artículo 1644 del Código de Comercio $^{30}$. De igual forma se pronunció el Tribunal de Bogotá en sentencia del 11 de febrero de $1977^{31}$. Finalmente, en la decisión del 28 de noviembre de 1984 del Tribunal Superior del Distrito de Bogotá no se aceptan limitaciones irrisorias o que sean muy bajas ${ }^{32}$.

En concordancia con lo expuesto, es dable deducir que esta situación analizada frente a la sentencia del 8 de septiembre de 2011 no solo podría presentarse en el transporte marítimo, pues en el transporte aéreo donde legalmente las limitaciones de responsabilidad son claras, ocurren situaciones similares a las que se presentan en los numerales anteriores, con las cuales igualmente de acuerdo con la Sentencia estudiada, se estaría siempre declarando un valor.

30 Corte Suprema de Justicia, Sala de Casación Civil. Sentencia del 22 de enero de 1991. M.P Eduardo García Sarmiento.

31 Tribunal Superior del Distrito Judicial de Bogotá. Sentencia del 11 de febrero de 1977. M.P. Hugo Vela Camelo.

32 Tribunal Superior del Distrito de Bogotá. Sentencia del 28 de noviembre de 1984. 


\subsection{Análisis de la Jurisprudencia en Panamá}

Por su parte, contrario a lo que sucede en los dos países latinoamericanos antes estudiados, el asunto de la limitación de responsabilidad en Panamá parece ser bastante claro.

Como ejemplo de lo anterior, la Corte Suprema de Justicia, Sala Civil en Sentencia del 27 de Julio de 2001, Magistrado Ponente Rogelio A. Fábrega Z. establece la indemnización a partir de lo establecido en las Reglas de la Haya Visby:

“... el límite de responsabilidad por bulto, consagrado en las Reglas de La Haya Visby, fue determinado por el juzgador, de acuerdo a(sic) las constancias en autos, en base al(sic) valor de dos bultos, cuya limitación de cada uno de ellos se fijó en 666.67 SDRs ó OCHOCIENTOS OCHENTA Y NUEVE DOLARES CON SETENTA Y SIETE CENTÉSIMOS (US\$889.77), conforme a las reglas del Convenio de la Haya-Visby..." ${ }^{33}$

De otro lado, en Sentencia del 21 de Julio de 2008 de la Corte Suprema de Justicia, Magistrado Ponente Harley James Mitchell D. además de lo relativo a límites de responsabilidad, trata otros temas relacionados en los tratados internacionales para el transporte de mercancías y se sigue evidenciando un total apego a lo establecido en estas.

En cuanto al término de prescripción, la Corte Panameña señala lo siguiente:

"...en virtud de que en el reverso de dichos conocimientos se encuentra una cláusula Paramount y de responsabilidad del transportista que señala "el contrato evidenciado en este Conocimiento de Embarque tendrá efecto sujeto a las reglas de la Haya", es aplicable el término de prescripción de un año." ${ }^{34}$

\subsection{Análisis de la Jurisprudencia en Estados Unidos}

En el caso de los Estados Unidos, este es parte del Convenio de Montreal sobre transporte aéreo pero no es parte de los protocolos adicionales al Convenio de Bruselas de 1924 respecto del transporte marítimo. Estados Unidos adoptó las Reglas de la Haya a través del Carriage of Goods by

33 Corte Suprema de Justicia, Sala Civil. Sentencia del 27 de Julio de 2001, Magistrado Ponente Rogelio A. Fábrega Z.

34 Corte Suprema de Justicia, Sala Civil. Sentencia del 21 de Julio de 2008. Magistrado Ponente Harley James Mitchell D. 
Sea Act de 1936 (COGSA), pero no sus respectivas modificaciones que las diferencian con el nombre de Reglas de la Haya-Visby. Las cortes de Estados Unidos han buscado proteger los acuerdos internacionales a los que han llegado con el fin de tener una unidad en la normatividad que busca la regulación del transporte marítimo:

"Kirby explicó que "siempre y cuando un bill of lading tiene una parte sustancial de transporte maritimo, su propósito es efectuar comercio marítimo". Id., 27. La Corte añadió que "(a)plicando las leyes estatales a casos como este socava la uniformidad del derecho marítimo general" Id., at 28 "Confusión e ineficiencia van a resultar inevitablemente si más de un cuerpo normativo regula el sentido de un contrato" Id., et at 29. La Corte anota que su conclusión "refuerza el régimen de responsabilidad establecido por el Congreso en COGSA" y explica que COGSA permite a las partes extender sus límites y términos a una porción terrestre de transporte de una travesía bajo un through bill of lading ",35

Las interpretaciones que se han hecho siempre buscan legitimar y beneficiar la uniformidad de las normas que recaen sobre transporte internacional y la costumbre mercantil:

"Kirby anotó "la popularidad de los through bills of lading, en los cuales los cargadores pueden contratar transporte a través de los océanos incluyendo porciones terrestres en una sóla transacción" 543 U.S., at 25-26. La Corte no ve ninguna razón para interpretar COGSA y Carmack con el fin de prohibir esta eficiente forma de transporte internacional requiriendo que estos viajes tengan multiples bills of lading",36

Se prefiere por parte de la Corte tener un régimen de responsabilidad estándar, aún este régimen sea menos favorable para el cargador; de haberse aplicado las normas del Carmack, este hubiera tenido una indemnización mayor que bajo la aplicación de las normas del COGSA. Adicionalmente, la complejidad de determinar donde ocurre el daño o el régimen legal aplicable hace que la Corte prefiera aplicar un régimen estándar:

"Si Carmack aplica para un segmento de transporte terrestre respecto de un envio internacional bajo un through bill, entonces habría un régimen de responsabilidad y de reglas para el caso en que el daño sea causado en el mar

35 Supreme Court of The United States. KAWASAKI KISEN KAISHA LTD. ET AL. v. REGALBELOIT CORP. ET AL. No. 08-1553. Pp. 8. Obtenido el 20 de junio de 2016 de: http://www. supremecourt.gov/opinions/09pdf/08-1553.pdf. Traducción libre de los autores

36 Supreme Court of The United States. KAWASAKI KISEN KAISHA LTD. ET AL. v. REGALBELOIT CORP. ET AL. No. 08-1553. Pp. 17. Obtenido el 20 de junio de 2016 de: http://www. supremecourt.gov/opinions/09pdf/08-1553.pdf. Traducción libre de los autores 
(COGSA) y otro cuando el daño sea causado en tierra (Carmack). En vez de hacer los reclamos por los cargadores más fáciles de resolver, una corte tendría que decidir en primera instancia donde ocurrió el daño para determinar la norma aplicable. Desde un punto de vista práctico, este requerimiento no podría ser cumplido en todos los casos; el daño del contenido de los contenedores puede ocurrir por malos manejos, filtraciones o robo en un momento desconocido. Ver H. Kindred \& M. Brooks, Multimodal Transport Rules 143 (1997). De hecho adoptar la decisión de la Corte de Apelaciones requeriría que los transportadores ferroviarios abrieran los contenedores en puerto con el fin de revisar si el daño se presentó durante el transporte marítimo. Esta disrupción socavaría el transporte internacional basado en contenedores. ",37

Este análisis también fue realizado en el mencionado caso de NORFOLK SOUTHERN RAILWAY CO. v. JAMES N. KIRBY, PTY LTD., DBA KIRBY ENGINEERING, ET AL. ${ }^{38}$, donde se decidió que aplican las normas que establecen la limitación de la responsabilidad, incluyendo aquellas que se derivan de una cláusula Himalaya ${ }^{39}$. La limitación de responsabilidad establecida en el BL emitido en el caso en estudio se decidió que aplicaba tanto para el transportador marítimo (Hamburg Süd) como para Norfolk.

En el caso de TWA vs Franklin Corp ${ }^{40}$, la Corte Suprema analizó los límites de responsabilidad contenidos en la Convención de Varsovia sobre el transporte aéreo para el caso de la pérdida de 178 paquetes con monedas numismáticas. De acuerdo con el análisis realizado por la Corte, se aplica la limitación contenida en la convención por más que haya sido modificada desde su promulgación, en especial por el cambio por el equivalente a valor oro al de los derechos especiales de giro. Nuevamente dentro del análisis realizado por la Corte se establece la importancia de unas reglas claras a partir de un límite de responsabilidad estable, predecible y establecido de manera internacional para permitir el desarrollo y crecimiento de la industria aeronáutica:

37 Supreme Court of The United States. KAWASAKI KISEN KAISHA LTD. ET AL. v. REGALBELOIT CORP. ET AL. No. 08-1553. Pp. 17-18. Obtenido el 20 de junio de 2016 de: http://www. supremecourt.gov/opinions/09pdf/08-1553.pdf. Traducción libre de los autores.

38 Supreme Court of the United States. NORFOLK SOUTHERN RAILWAY CO. v. JAMES N. KIRBY, PTY LTD., DBA KIRBY ENGINEERING, ET AL. No. 02-1028. Obtenido el 20 de junio de 2016. http://www.admiraltylawguide.com/supct/Norfolksouthern.pdf\#search=Liability

39 Cláusula usualmente incluida en los BL o contratos de transporte donde se establece que las limitaciones de responsabilidad como las condiciones pactadas en dicho documento se aplican para los transportadores subcontratados por este.

40 Supreme Court of the United States. Trans World Airlines, Inc. v. Franklin Mint Corp. No. 82-1186. Obtenido el 27 de mayo de 2016 de: https://supreme.justia.com/cases/federal/us/466/243/ 
"Una limitación de responsabilidad de \$9.07 por libra representa una decisión que no contraria el propósito de la Convención de establecer un régimen de responsabilidad del transportador estable, predecible y uniforme internacionalmente con el fin de promover la industria del transporte aéreo." 41

Esta opinión de la Corte vuelve a presentarse en el análisis de la aplicación de una cláusula de arbitraje internacional para resolver un caso regulado por COGSA y que tiene como trasfondo la limitación de responsabilidad de un transportador:

"A partir del hecho que COGSA es la culminación de un esfuerzo multilateral para "establecer bills of lading uniformes para gobernar los derechos y responsabilidades de los transportadores y cargadores en el comercio internacional" Robert C. Herd \& Co. V. Krawill Machinery Corp., 359 U.S. 297, 301 (1959) declinamos interpretar nuestra propia versión de las Reglas de la Haya en una forma contraria a cualquier otra nación que ha solucionado esta situación. Ver Sturley,supra, at 736 (conflictos en la interpretación de las Reglas de la Haya no solo destruyen simetría en el orden legal internacional sino que imponen costos reales en el sistema comercial que las Reglas gobiernan). " ${ }^{42}$

Es claro que, al igual que Francia, los Estados Unidos buscan mantener una uniformidad en la normatividad aplicable a este tipo de transportes, prefiriendo en los casos mencionados, la aplicación de las convenciones internacionales sobre normatividad interna de los mismos países. Para Estados Unidos es muy importante que, con el fin de mantener una simetría en la aplicación de las normas y por lo tanto una clara seguridad jurídica, los casos que se presentan ante sus cortes reflejen esto. No es raro que para decidir un caso, las cortes de Estados Unidos consulten las decisiones tomadas en otras jurisdicciones en casos similares.

\subsection{Análisis de la Jurisprudencia en el Reino Unido}

Es importante poner de presente la relevancia que se le da a las convenciones internacionales en el Reino Unido. En el caso de The "Hollandia" ("Morviken") (1983) ${ }^{43}$, se estudia el caso en que las Reglas de la

41 Ibídem

42 Supreme Court of the United States. VIMAR SEGUROS Y REASEG. v. M/V SKY REEFER No. 94-623. Obtenido el 20 de junio de 2016 de: https://www.law.cornell.edu/supremecourt/text/515/528. Traducción libre de los autores.

43 The "Hollandia" ("Morviken") (1983). En The Owners of the Ships or Vessels "Djatianom" et al v. The Owners of Cargo Lately Laden on the Ship or Vessel "Benarty" P.T. Djakarta Lloyd v. R.A. Lister and Company Limited and Others In the Supreme Court of Judicature Court of Appeal (Civil Division) On Appeal from an Order of Mr Justice Sheen 15 July 19841984 WL 988541. 
Haya-Visby vigentes en el Reino Unido no vayan a ser aplicadas por un acuerdo de jurisdicción aplicable entre las partes. En el caso de Hollandia, las partes acordaron una cláusula de jurisdicción aplicable en la que se debía solucionar el caso en Amsterdam de acuerdo con las leyes holandesas. Ahora bien, para el momento del caso, Holanda sólo había aceptado las Reglas de la Haya, no había adoptado los Protocolos adicionales que reformaron estas reglas. Este caso se trataba del transporte de una máquina asfaltadora desde Leith, Escocia, hasta Bonaire en las Antillas Holandesas. Cuando se estaba descargando la máquina, se le causó un daño que se estimaba en 22.000 Libras Exterlinas. De aplicarse la cláusula de jurisdicción del BL, se estaría cubriendo, de acuerdo con los límites de responsabilidad, sólo 250 Libras Exterlinas. El Cargador decidió demandar ante las cortes del Reino Unido el presente caso, el cual llegó como última instancia al House of Lords, donde se decidió que la aplicación de la cláusula de jurisdicción pactada es contraria a la mismas Reglas de la Haya, ya que el artículo III Numeral Octavo de las Reglas de la Haya Visby establecen que cualquier cláusula o acuerdo establecido en el contrato de transporte que busque relevar al transportador o al buque de su responsabilidad por perdida o daño de los bienes o limitar la extensión de la responsabilidad en contra de lo establecido en las Reglas de la Haya-Visby, será nula y carente de cualquier efecto ${ }^{44}$. Por lo tanto, se decidió por el House of Lords que se debía aplicar las Reglas de la Haya-Visby y el caso se debía llevar ante las Cortes del Reino Unido.

De la misma forma se entiende la importancia de estas convenciones para el comercio internacional. En el caso de Corocraft Ltd v Pan American Airways Inc ${ }^{45}$, la corte de apelaciones revisó decisiones inter-

Obtenido el 15 de julio de 2016 de: https://1-next-westlaw-com.ezproxy.javeriana.edu.co/Document/ IAB9F58F2466E11E280E3FD836630D9CB/View/FullText.html?navigationPath=Search\%2Fv3\% 2Fsearch $\% 2$ Fresults $\% 2$ Fnavigation $\% 2$ Fi0ad7401100000155f1410a 5 cdeb30c $77 \% 3$ FNav $\% 3$ DINTE RNATIONAL-CASES\%26fragmentIdentifier\%3DIAB9F58F2466E11E280E3FD836630D9CB\%2 6startIndex\%3D1\%26contextData\%3D\%2528sc.Search\%2529\%26transitionType\%3DSearchItem \&listSource $=$ Search\&listPageSource $=$ caa3392f692314196fd7dd7bdd7b6c91\&list=INTERNATION AL-CASES\&rank=8\&grading=na\&sessionScopeId=34d668ccc2602ed63e2057558f76fe44b3994de 13c4dff76f085dbbe9edcd565\&originationContext=Search\%20Result\&transitionType=SearchItem\& contextData $=\% 28 \mathrm{sc}$. Search $\% 29$

44 Reglas de la Haya-Visby http://www.jus.uio.no/lm/sea.carriage.hague.visby.rules.1968/doc.html\#11

45 Corocraft Ltd v Pan American Airways Inc. Court of Appeal. November 7, 1968[1969] 1 Q. Obtenido el 24 de julio de 2016 de https://1-next-westlaw-com.ezproxy.javeriana.edu.co/Document/ I8EB58851E42711DA8FC2A0F0355337E9/View/FullText.html?navigationPath=Search\%2Fv3\%2F search\%2Fresults\%2Fnavigation\%2Fi0ad70524000001561e913237efbaabba\%3FNav\%3DINTERN ATIONAL-CASES\%26navQualifier\%3DI6a46a750a09611e28578f7ccc38dcbee\%26fragmentIdenti 
nacionales con el fin de conocer como se había abordado casos similares en otras jurisdicciones. El asunto sometido a conocimiento de la corte era si se aplicaban o no los límites de responsabilidad establecidos en la Convención de Varsovia por no haber incluido el transportador las dimensiones del paquete en el Airway Bill.

"Si las cortes inglesas llegasen a hesitar en adoptar una aproximación tan robusta como se dio en el caso de American Smelting, no es porque las cortes estén menos al tanto de las necesidades de la comunidad de comerciantes" ${ }^{46}$

"Esta es una convención multilateral que aplica en muchos más países que usan un sistema civil de leyes que nuestro sistema por lo que una aproximación más amplia es apropiada en un mundo moderno cada vez más conectado. Esta es la actitud de los Estados Unidos. Puede que esta no sea nuestra aproximación pero es provechoso tener uniformidad. ${ }^{47}$

"Este es un campo en el que lo más lamentable sería tener divergencias entre las aproximaciones de las cortes de los Estados Unidos y las del Reino Unido..."

Es claro que para la Corte de Apelaciones, es importante buscar uniformidad con el fin que haya una seguridad jurídica para los comerciantes sin importar la jurisdicción a la que acudan para solucionar sus controversias. Por esto, a lo largo del fallo, se analizó jurisprudencia internacional, doctrina y se preguntó en la práctica la importancia de incluir las dimensiones de la carga en el Airway Bill. Después de decantar lo anterior, La corte de apelaciones siguió la decisión tomada en el caso de American Smelting \& Refining Co. V. Philippine Air Lines Inc ${ }^{49}$ por

fier\%3DI8EB58851E42711DA8FC2A0F0355337E9\%26startIndex\%3D1\%26contextData\%3D\%25 28sc.Search\%2529\%26transitionType\%3DSearchItem\%26listQualifier\%3DI6a46a750a09611e2857 $8 \mathrm{f} 7 \mathrm{ccc} 38 \mathrm{dcbee} \&$ listSource $=$ Search\&listPageSource $=\mathrm{d} 5 \mathrm{a} 9 \mathrm{~d} 89 \mathrm{fa} 979 \mathrm{bb} 1 \mathrm{c} 98 \mathrm{abd} 95 \mathrm{f} 851 \mathrm{c} 1 \mathrm{e} 50 \&$ list $=\mathrm{IN}$ TERNATIONAL-CASES\&rank $=2 \&$ grading $=$ na\&sessionScopeId $=\mathrm{d} 25 \mathrm{cb} 2 \mathrm{e} 83176 \mathrm{~b} 4 \mathrm{c} 23 \mathrm{e} 600 \mathrm{f} 0 \mathrm{~d} 0 \mathrm{da}$ 2b523dd9285bdfcb16010d1486b7e1387244d\&originationContext=Search\%20Result\&transitionTyp $\mathrm{e}=$ SearchItem\&contextData $=\% 28 \mathrm{sc}$. Search $\% 29$

Ibídem. Pp. $638-639$.

47 Ibídem. Pp. 645

48 Ibídem. Pp. 628

49 New York Court of Appeals. American Smelting \& Refining Co. V. Philippine Air Lines Inc [1954] U.S. \& Ca.Av.Rep. 221. En Corocraft Ltd v Pan American Airways Inc. Court of Appeal November 7, 1968[1969] 1 Q. Obtenido el 24 de julio de 2016 de https://1-next-westlaw-com.ezproxy.javeriana. edu.co/Document/I8EB58851E42711DA8FC2A0F0355337E9/View/FullText.html?navigationPath $=$ Search $\% 2 \mathrm{Fv} 3 \% 2 \mathrm{Fsearch} \% 2 \mathrm{Fresults} \% 2 \mathrm{Fnavigation} \% 2 \mathrm{Fi} 0 \mathrm{ad} 70524000001561 \mathrm{e} 913237 \mathrm{efbaabba} \% 3$ FNav\%3DINTERNATIONAL-CASES\%26navQualifier\%3DI6a46a750a09611 e28578f7ccc38dcbe e\%26fragmentIdentifier\%3DI8EB58851E42711DA8FC2A0F0355337E9\%26startIndex\%3D1\%26c ontextData\%3D\%2528sc.Search\%2529\%26transitionType\%3DSearchItem\%26listQualifier\%3DI6a 46a750a09611e28578f7ccc38dcbee\&listSource $=$ Search\&listPageSource $=\mathrm{d} 5 \mathrm{a} 9 \mathrm{~d} 89 \mathrm{fa} 979 \mathrm{bb} 1 \mathrm{c} 98 \mathrm{abd} 9$ 5f851c1e50\&list=INTERNATIONAL-CASES\&rank=2\&grading=na\&sessionScopeId=d25cb2e 831 
la Corte de Apelaciones de Nueva York, con el fin de buscar esta uniformidad, ya que de apartarse del mismo, se cambiaría por completo la posibilidad de indemnización a la que puede tener derecho el cargador:

"Hay una razón muy práctica para hacer esto. El remitente en este caso podría iniciar una acción en contra de Pan American Airlines tanto en Nueva York como en Londres: ver artículo $26 \mathrm{~g}$ de la Convención. El resultado debería ser el mismo en cualquier caso. Sería absurdo que el remitente podría recuperar $£ 1,194$ 13s. $8 d$ si demanda en Londres y sólo £19 2s. lOd (o su equivalente en dólares) si demanda en Nueva York. Nosotros evitamos este absurdo siguiendo la aproximación (al caso) de los Estados Unidos. ${ }^{50}$ "

Sin embargo, la decisión en Corocraft Ltd v Pan American Airways Inc. y la importante y juiciosa revisión de las sentencias internacionales y doctrina no siempre se ha seguido por otras decisiones en las cortes del Reino Unido. En el caso de Daewoo Heavy Industries vs Klipriver Shipping Ltd ${ }^{51}$ se analiza por parte de la Corte de Apelaciones si se aplica o no la limitación a un daño generado en una mercancía por ser transportada sobre cubierta, en contra de la solicitud expresa del cargador de transportarla bajo cubierta. De acuerdo con el análisis, se decide por parte de la Corte de Apelaciones que en el caso particular no hay una infracción tan grande de las obligaciones del transportador, por lo que se aplican las limitaciones contenidas en las Reglas de la Haya.

Como en el caso de Corocraft y Pan American, esta decisión analiza otras sentencias que han revisado situaciones similares en donde se ha causado daño por el transporte de la mercancía sobre la cubierta del bar-

76b4c23e600f0d0da2b523dd9285bdfcb16010d1486b7e1387244d\&originationContext=Search\%20 Result\&transitionType $=$ SearchItem\&contextData $=\% 28 \mathrm{sc}$. Search\%29. Traducción libre de los autores.

50 Corocraft Ltd v Pan American Airways Inc. Court of Appeal November 7, 1968[1969] 1 Q. Pp. 655Obtenido el 24 de julio de 2016 de https://1-next-westlaw-com.ezproxy.javeriana.edu.co/ Document/I8EB58851E42711DA8FC2A0F0355337E9/View/FullText.html?navigationPath=Search \%2Fv3\%2Fsearch\%2Fresults\%2Fnavigation\%2Fi0ad70524000001561e913237efbaabba\%3FNav\% 3DINTERNATIONAL-CASES\%26navQualifier\%3DI6a46a750a09611e28578f7ccc38dcbee\%26fra gmentIdentifier\%3DI8EB58851E42711DA8FC2A0F0355337E9\%26startIndex\%3D1\%26contextDa ta\%3D\%2528sc.Search\%2529\%26transitionType\%3DSearchItem\%26listQualifier\%3DI6a46a750a0 9611 e28578f7ccc38dcbee\&listSource $=$ Search\&listPageSource $=\mathrm{d} 5 \mathrm{a} 9 \mathrm{~d} 89 \mathrm{fa} 979 \mathrm{bb} 1 \mathrm{c} 98 \mathrm{abd} 95 \mathrm{f} 851 \mathrm{c} 1 \mathrm{e}$ $50 \&$ list=INTERNATIONAL-CASES\&rank $=2 \&$ grading $=$ na\&sessionScopeId $=\mathrm{d} 25 \mathrm{cb} 2 \mathrm{e} 83176 \mathrm{~b} 4 \mathrm{c} 23 \mathrm{e}$ 600f0d0da2b523dd9285bdfcb16010d1486b7e1387244d\&originationContext=Search\%20Result\&tra nsitionType $=$ SearchItem\&contextData $=\% 28 \mathrm{sc}$. Search $\% 29$. Traducción libre de los autores.

51 Daewoo Heavy Industries Ltd \& Anr v. Klipriver Shipping Ltd \& Anr 20021554 A3 Court of Appeal (Civil Division) 3 Obtenido el 15 de julio de 2016 de: https://1-next-westlaw-com.ezproxy.javeriana. edu.co/Document/I93C4B2D0E42711DA8FC2A0F0355337E9/View/FullText.html?transitionType= SearchItem\&contextData=(sc.Search)April 2003. 
co. En otras decisiones ${ }^{52}$, se ha determinado (como se hizo por la Corte Suprema de Francia respecto del caso SAGA FRANCE y COMPAGNIE MORBIHANNAISE ET NANTAISE DE NAVIGATION (C.M.N.N) ${ }^{53}$ ) que la falta cometida por el transportador era grave y por lo tanto no se aplicaban los límites de indemnización contenidos en las Reglas de la Haya-Visby. Se presenta, en este caso entonces, una diferencia sustancial respecto de la indemnización que puede obtener el cargador dependiendo de la jurisdicción donde demande y no se consigue una uniformidad de las decisiones frente a casos similares, impactando de esta forma la uniformidad y seguridad jurídica que requieren el comercio internacional.

En el caso de Quantum Corp Inc v Plane Trucking Ltd, 2001 WL $272987(2001)^{54}$, se analizó por la Corte el caso de un transporte que se realizó por Air France pero que en una parte del trayecto subcontrató a Plane Trucking para realizar parte del trayecto (de Paris a Dublin) de manera terrestre. Los bienes objeto del transporte sufrieron daños en el transporte terrestre. Air France reconoció su responsabilidad, pero limitó la misma a lo establecido por la Convención de Varsovia (17 DEG por kilogramo). La Corte aceptó que la responsabilidad de Air France se limitara a este monto de acuerdo con dicha convención internacional. No aceptó es que la limitación contenida en la Convención de Varsovia aplicara para el transportador terrestre a partir de una cláusula Himalaya. Esta decisión es contraria a lo establecido por la Corte Suprema de Estados Unidos, que decidió que a partir de un Through Bill of Lading si se podían aplicar las normas de COGSA para una porción terrestre

52 The Chanda (1989) 2 Lloyds Rep 494. En Daewoo Heavy Industries Ltd \& Anr v. Klipriver Shipping Ltd \&Anr 2002 1554A3 Court of Appeal (Civil Division) 3 Obtenido el 15 de julio de 2016 de: https://1-nextwestlaw-com.ezproxy.javeriana.edu.co/Document/I93C4B2D0E42711DA8FC2A0F0355337E9/ View/FullText.html?transitionType=SearchItem\&contextData=(sc.Search)April 2003.

53 Cour d'appel de Versailles, du 30 mars 2000, $\mathbf{N}^{\circ}$ de RG: 1997-3796 Obtenida el 6 de mayo de 2016 de https://www.legifrance.gouv.fr/affichJuriJudi.do?oldAction=rechJuriJudi\&idTexte=JURITEXT00 0006936432\&fastReqId $=4046634 \&$ fastPos $=29$

54 Quantum Corp Ltd \& Ors v. Plane Trucking Ltd \& Anor. Queen's Bench Division (Commercial Court)10 April 2001. Obtenido el 15 de julio de 2016 de: https://1-next-westlaw-com.ezproxy. javeriana.edu.co/Document/IC9C9FE50E4B611DAB61499BEED25CD3B/View/FullText.html?nav igationPath=Search $\% 2 \mathrm{Fv} 3 \% 2 \mathrm{Fsearch} \% 2 \mathrm{Fresults} \% 2 \mathrm{Fnavigation} \% 2 \mathrm{Fi} 0 \mathrm{ad} 6 \mathrm{ad} 3 \mathrm{e} 000001560 \mathrm{bd} 9623 \mathrm{~d} 3$ fef6c39\%3FNav\%3DINTERNATIONAL-CASES\%26navQualifier\%3DI1dec5f10a08911e28578f7c cc38dcbee\%26fragmentIdentifier\%3DIC9C9FE50E4B611DAB61499BEED25CD3B\%26startIndex \%3D1\%26contextData\%3D\%2528sc.Search\%2529\%26transitionType\%3DSearchItem\&listSource= Search\&listPageSource=4d994528e684421b976f34f4ca352379\&list=ALL\&rank=1\&grading=na\&s essionScopeId=9cc2ae390084069d1952f551 f923e 73cc2e091870461a03cc9e9a53f3a96e338\&origin ationContext $=$ Search\%20Result\&transitionType $=$ SearchItem\&contextData $=\% 28 \mathrm{sc}$. Search $\% 29$ 
del transporte ${ }^{55}$, al igual que bajo una cláusula Himalaya en el caso de NORFOLK SOUTHERN RAILWAY CO. v. JAMES N. KIRBY, PTY LTD., DBA KIRBY ENGINEERING, ET AL ${ }^{56}$.

Esto no quiere decir que las decisiones de las cortes en el Reino Unido no respeten y velen por la aplicación de las convenciones internacionales. Como ejemplo, En Fujitsu Computer Products Corp v Bax Global Inc, ${ }^{57}$ la Corte de Apelaciòn no aplicó la limitación de responsabilidad porque el BL no cumplía con las reglas contenidas en la Convención sobre la inclusión clara que este Airway Bill se regula por la convención de Varsovia y que por lo tanto se establece una limitación de responsabilidad del transportador, salvo que se declare el valor total de la mercancía. El Airway Bill no era claro en su redacción para establecer esta limitación, por lo que se negó la posibilidad de aplicar las normas de la Convención al respecto.

\section{CONCLUSIONES}

A partir del análisis de la jurisprudencia de estas seis naciones, se pueden realizar las siguientes conclusiones y recomendaciones para las aseguradoras que explotan el ramo de los seguros de transporte de carga.

La posibilidad de recuperación que pueda tener una aseguradora frente a un siniestro derivado de un contrato de transporte internacional, se desprende en primer lugar, del modo de transporte y del lugar

55 Supreme Court of The United States. KAWASAKI KISEN KAISHA LTD. ET AL. v. REGALBELOIT CORP. ET AL. No. 08-1553. Pp. 8. Obtenido el 20 de junio de 2016 de: http://www. supremecourt.gov/opinions/09pdf/08-1553.pdf

56 Supreme Court of the United States. NORFOLK SOUTHERN RAILWAY CO. v. JAMES N. KIRBY, PTY LTD., DBA KIRBY ENGINEERING, ET AL. No. 02-1028. Obtenido el 20 de junio de 2016. http://www.admiraltylawguide.com/supct/Norfolksouthern.pdf\#search=Liability

57 Fujitsu Computer Products Corp, Fujitsu Limited, Fujitsu Europe Limited v. B.AX Global Inc, Bax Global (UK) Limited, Bax Global Limited, Bax Global Limited, Bax Global Inc, Bax Global Inc Case No: 2003 Folio No 595 High Court of Justice Queen's Bench Division Commercial C. Obtenido el 15 de julio de 2016 de https://1-next-westlaw-com.ezproxy.javeriana.edu.co/Document/ IABF81270E42711DA8FC2A0F0355337E9/View/FullText.html?navigationPath=Search\%2Fv3\% 2Fsearch\%2Fresults\%2Fnavigation\%2Fi0ad7401100000155f1410a5cdeb30c77\%3FNav\%3DINTE RNATIONAL-CASES\%26fragmentIdentifier\%3DIABF81270E42711DA8FC2A0F0355337E9\%2 6startIndex\%3D1\%26contextData\%3D\%2528sc.Search\%2529\%26transitionType\%3DSearchItem $\&$ listSource $=$ Search $\&$ listPageSource $=$ caa3392f692314196fd7dd7bdd7b6c91\&list=INTERNATION AL-CASES\&rank $=6 \&$ grading $=$ na\&sessionScopeId $=34 \mathrm{~d} 668 \mathrm{ccc} 2602 \mathrm{ed} 63 \mathrm{e} 2057558 \mathrm{f} 76 \mathrm{fe} 44 \mathrm{~b} 3994 \mathrm{de}$ 13c4dff76f085dbbe9edcd565\&originationContext=Search\%20Result\&transitionType=SearchItem\& contextData $=\% 28$ sc. Search $\% 29$ 
en donde se presentó el siniestro. Como ejemplo, generalmente en el ámbito terrestre por carretera no hay limitaciones de responsabilidad, en especial en la jurisdicción colombiana. Contrario a esto, en Europa si se aplica claramente las limitaciones contenidas en la Convención CMR de transporte terrestre, siendo ejemplo de esto es la sentencia del 2 de octubre de 2003 de la Corte de Apelación de Versalles.

En transporte marítimo, las decisiones de todos los países analizados, salvo Colombia y Brasil, se rigen por las convenciones internacionales o por la versión que tengan de estas (caso de los Estados Unidos con el COGSA). En Colombia y en Brasil no hay una cultura de respeto a estas normas, entre otras, porque ninguno de los dos países hace parte de ellas. Esto claramente afecta la interiorización de estos acuerdos en el ordenamiento interno y especialmente en los jueces. Para ambos países se encontraron decisiones judiciales que se contradicen y que amplían la falta de claridad y de inseguridad jurídica para el gremio transportador y asegurador.

En cambio, se ve de manera clara y expresa como en varias sentencias de Panamá, Estados Unidos y del Reino Unido se analiza la jurisprudencia internacional de casos similares con el fin lograr una seguridad jurídica y una jurisprudencia similar sin importar la plaza judicial a donde se lleve el caso.

Sin embargo, esta búsqueda de la uniformidad se ve truncada por la interpretación que se le puede dar en un ámbito o en otro a una situación, como en el caso de la inclusión de los límites de transporte de una convención internacional en un transporte interno a través de una cláusula Himalaya. En Estados Unidos se falló teniendo en cuenta los límites, pero en el Reino Unido no.

Otro asunto que va en contra de la uniformidad son las mismas fuentes de los derechos internos y que afectan la interpretación que hacen los países de estos acuerdos internacionales. No se entiende de una misma manera un error grave o inexcusable por Francia, que deriva su sistema legal del derecho civil, al Reino Unido, cuyo sistema proviene del Common Law. En dos casos muy similares, se fallaron de manera muy distinta en ambas jurisdicciones y la razón de esto fue la interpretación del término de culpa grave o error inexcusable que hace inoperantes los límites de las Reglas de la Haya-Visby. 
La diversidad de convenios internacionales que hay regulando el transporte marítimo hace que las diferencias respecto del límite de responsabilidad sean importantes. De acuerdo con el estudio realizado por William Tetley ${ }^{58}$, hay por lo menos nueve límites de responsabilidad: i) los de las Reglas de la Haya; ii) los de las Reglas de la HayaVisby sin el Protocolo SDR; iii) los de las Reglas de la Haya-Visby con el Protocolo SDR; iv) los de las Reglas de Hamburgo; v) los de US COGSA; vi) las conversiones de los límites de las Reglas de la Haya (100 libras exterlinas oro) en moneda local y en su valor en oro; vii) las conversiones del valor del Franco Pointcarré en moneda local como en valor oro; viii) los límites de los países que no hacen parte de las convenciones internacionales, entre ellos Colombia y ix) Los que aplican límites locales a los convenios internacionales. Esto implica un claro problema para la búsqueda de una uniformidad internacional respecto de la solución por reclamos derivados de daños o pérdidas a la carga en el transporte marítimo. Esta cantidad de normas y aplicaciones de las mismas, se transfieren en una posibilidad muy grande de tener decisiones desiguales aplicando límites diferentes y presentándose la situación -que se menciona en varias sentencias de los Estados Unidos y del Reino Unido- que un caso puede fallarse (respecto de los límites) de manera más favorable para una u otra parte dependiendo de la jurisdicción. Se vuelve, en estas situaciones, sumamente importante la decisión de las partes respecto de lo pactado contractualmente.

Ahora bien, al ser los conocimientos de embarque usualmente contratos de adhesión, queda en manos de los cargadores de negociar con el transportador el fórum ante el cual se decidirá el caso y la legislación aplicable. Se vuelve sumamente importante la negociación y suscripción del contrato ante las circunstancias analizadas. Por esto, es importante que, la aseguradora acompañe a su cliente desde el mismo momento de la negociación del contrato, con el fin que ella también tenga conocimiento de lo pactado contractualmente y un conocimiento de lo que podría pasar de ser necesaria una subrogación en contra del transportador.

58 Tetley, W. (1995). Package \& Kilo Limitations and The Hague, Hague/Visby and Hamburg Rules \& Gold. Journal of Maritime Law \& Commerce. January, 1995. 26 J. Mar. L. \& Com. 133. Obtenido el 31 de julio de 2016 de: http:/www.lexisnexis.com.ezproxy.javeriana.edu.co:2048/hottopics/ lnacademic/? 
En especial para el caso de Brasil, es muy importante que las aseguradoras conozcan la jurisprudencia de los casos, con el fin de tener en cuenta los antecedentes en los cuales se han establecido indemnizaciones totales por existir una relación de consumo. Por más que para la seguridad jurídica en transporte internacional la situación que se está presentando en este país es nefasta, desde el punto de vista de las aseguradoras es sumamente interesante ya que tienen la oportunidad de poder de manos del transportador la suma total de la indemnización pagada a su asegurado.

Por esta serie de razones, no se puede hablar de un verdadero régimen o regulación sobre transporte marítimo actualmente. En nuestra opinión lo que existen es una serie de colchas de retazos que pueden aplicar en respectivos casos. Para la carga cuyo puerto de destino o de origen se encuentra en Colombia, las aseguradoras deben conocer claramente lo que a lo que se pueden enfrentar, que puede ir desde la obtención de sólo 500 dólares por paquete en US COGSA hasta el monto total de la carga en Brasil de aplicarse las normas del consumidor de este país en los casos en que el puerto de origen sea colombiano. Cuando el puerto de destino se encuentra en nuestro país, consideramos que es recomendable que Colombia se haga parte de alguno de los acuerdos internaciones sobre transporte marítimo con el fin de luchar en contra de la inseguridad jurídica que se está presentando en este medio de transporte sumamente importante para el país. En especial consideramos importante que se analice de manera juiciosa y de encontrarse beneficioso (situación que creemos es así), Colombia se haga parte de las Reglas de Rotterdam, que contiene muchas ventajas y ayuda a evitar parte de los problemas encontrados respecto de decisiones contrarias en casos similares.

En segundo lugar, la posibilidad de recuperación depende del tipo de mercancías que asegure. Para ilustrar; si un embarcador expide 1 kilo de oro con un valor de USD 500.000 por vía aérea, la indemnización de la aerolínea se limitará únicamente a 19 DEG por cada kilo, es decir que este expedidor o quien se subrogue sus derechos recibirá por un kilo de oro alrededor de USD 30.

Contrario al ejemplo anterior, si un cultivo de flores exporta por vía aérea una caja completa con un peso de $20 \mathrm{~kg}$, pero su valor apenas alcanza los USD 50. No obstante, el límite de responsabilidad es de USD 600 aproximadamente. En este caso, el límite de responsabilidad es su- 
perior al valor comercial, por lo cual el cultivo o su asegurador pueden recuperar el siniestro totalmente.

En último lugar, la posibilidad de recuperación depende del país donde se lleve a cabo el proceso de subrogación. Por ejemplo en Colombia se ha visto que existe la posibilidad de recuperar el total del valor de las mercancías. A pesar de esto, esta variable se pone en el último lugar teniendo en cuenta que la gran mayoría de los casos se resuelven prejudicialmente y generalmente en esferas comerciales se admite la existencia de los límites de responsabilidad (hasta ciertos topes monetarios).

Con base en lo anterior, a la hora de hacer cálculos, es importante que las aseguradoras tengan en cuenta el tipo de clientes que aseguran de acuerdo con el tipo de carga que estos manejan y con los países con los cuales tienes relaciones de comercio exterior.

Con el fin de garantizar un manejo más efectivo del riesgo, las aseguradoras que aseguren carga internacional, podrían incluso de manera preventiva establecer garantías según las cuales sus asegurados les permitan intervenir en la selección y elaboración de contratos de ser el caso con sus transportadores u operadores logísticos. Con esto, se busca una uniformidad en los riesgos que acepten las aseguradoras. Si bien existen los topes de los tratados internacionales, nos es de ninguna manera prohibido ampliarlos de manera contractual, lo cual puede permitir una mayor posibilidad de recuperación a la hora de un siniestro. Esta práctica no es para nada extraña en el comercio internacional.

En relación con los generadores de carga, este texto solo deja un mensaje claro: Para tener la completa seguridad de recibir una indemnización completa, sólo puede garantizarlo asegurando sus mercancías.

A excepción del transporte local en Colombia, de todas las sentencias analizadas, en ninguna se menciona la posibilidad de indemnizaciones por conceptos diferentes al daño emergente y la eventual actualización del monto correspondiente.

Teniendo en cuenta lo anterior, aunque los límites de responsabilidad resulten superiores al valor comercial de las mercancías, no se considera posible preliminarmente una indemnización por conceptos como lucro 
cesante, daños morales, entre otros. No existen impedimentos en las normas para buscar una compensación en ese sentido.

\section{BIBLIOGRAFÍA}

Benohma, M (2001). The Carriers Responsabilities and Immunities under The Hague and Hamburg Rules. Pp. V. Tesis de Grado para optar por el título de maestría en derecho (L.L.M.) de la Universidad de Montreal. Obtenido el 18 de febrero de 2016 de https://papyrus.bib.umontreal.ca/xmlui/bitstream/handle/1866/2637/11457597.PDF?sequence=1\&isAllowed=y

Comité Maritime International (CMI) Yearbook 2015 en: http://www.comitemaritime. org/Yearbooks/0,2714,11432,00.html

Comité Maritime International (CMI): THE TRAVAUX PRÉPARATOIRES OF THE INTERNATIONAL CONVENTION FOR THE UNIFICATION OF CERTAIN RULES OF LAW RELATING TO BILLS OF LADING OF 25 AUGUST 1924 THE HAGUE RULES AND OF THE PROTOCOLS OF 23 FEBRUARY 1968 AND 21 DECEMBER 1979 THE HAGUE-VISBY RULES. Obtenido el 29 de Julio de 2016 de: http://comitemaritime.org/Travaux-Pr\%C3\%A9paratoir es/0,27126,112632,00.html

Cheng, B. (2004). A new era in the law of international carriage by air: from Warsaw (1929) to Montreal (1999). International \& Comparative Law Quarterly. Pp. 833-859I.C.L.Q. 2004, 53(4).

Erling, S. (1981). Hamburg Rules, The Hague Rules and Marine Insurance Practice. Journal of Maritime Law and Commerce. Vol. 12, No. 3. Obtenido el 31 de Julio de 2016 de: http://heinonline.org.ezproxy.javeriana.edu.co:2048/HOL/ Page?handle $=$ hein.journals/jmlc12\&div $=24 \&$ start_page $=299 \&$ collection $=$ jou rnals\&set_as_cursor $=0 \& m e n \_t a b=$ srchresults

Fontestad (L). Tesis Doctoral sobre "El Transporte Marítimo de Mercancías y sus Incidencias Procesales”. Facultad de Derecho, Universidad de Málaga. Málaga, España

Franco Zárate, J. (2016). The International Comparative Legal Guide to Shipping Law. 4th Edition. Colombia Chapter. International Comparative Legal Guides (ICLG). Obtenido el 28 de julio de 2016 de: https://www.iclg.co.uk/practiceareas/shipping-law/shipping-law-2016\#general-chapters

Guzmán, J.V. (2007). El contrato de transporte marítimo de mercancías bajo conocimiento de embarque. Universidad Externado de Colombia. Bogotá, Colombia.

Guzmán, J.V. (2009). Contratos de Transporte. Universidad Externado de Colombia. Bogotá, Colombia 
Jiménez Valderrama F. (2011). El Sistema de Contratos de Explotación del Buque en el Código de Comercio Colombiano. Vniversitas, núm. 123, julio-diciembre, 2011, pp. 411-439. Pontificia Universidad Javeriana. Bogotá, Colombia

Jiménez Valderrama, F. (2015). Las Obligaciones del Porteador en el Contrato de Transporte Marítimo de Mercancías. Rev. chil. derecho vol.42 no.2 Santiago. Obtenida el 1 de agosto de 2016 de: http://www.scielo.cl/scielo.php?script=sci arttext\&pid=S0718-34372015000200006\#a05

IATA: A Universal Liability Regime For International Carriage by Air - Montreal Convention 1999. Obtenido el 1 de agosto de 2016 de: http://www.iata.org/ policy/Documents/Position-paper-mc99-dec\%202015\%20(2).pdf

Letacq, F. y Institut de Droit International des Transport. Droit applicable aux transports internationaux de marchandises. Artículo obtenido el 14 de febrero de 2016 en: http://www.idit.asso.fr/docenligne/documents/Regime $\% 20$ juridique $\% 20 \mathrm{des} \% 20$ TRANSPORTS\%20INTERNATIONAUX.pdf

Sturley, M.F. (1991). The history of COGSA and the Hague Rules. En Journal of Maritime Law and Commerce. Vol. 22. No. 1. Obtenido el 31 de Julio de 2016 de: http:// heinonline.org.ezproxy.javeriana.edu.co:2048/HOL/Page?handle=hein.journals/ jmlc22\&div $=8 \&$ start_page $=1 \&$ collection $=$ journals\&set_as_cursor $=0 \& m e n$ tab $=$ srchresults

Suescún, J. (1994). En International Conflicts of Laws (Common, Civil and Maritime) Pp. 895; William Tetley. Blais International Shipping Publications. Montreal

Sulicu, A. (2012). Aspects of Multimodal Transport in the Rotterdam Rules. Perspectives of Business Law Journal. Vol. 1, No. 1. Obtenido el 31 de julio de 2016 de: http://heinonline.org.ezproxy.javeriana.edu.co:2048/HOL/Page?handle=hein journals/perbularna1\&div $=7 \&$ start_page $=45 \&$ collection $=$ journals\&set_as cursor $=11 \&$ men $\_$tab $=$srchresults

Tetley, W. (1995). Package \& Kilo Limitations and The Hague, Hague/Visby and Hamburg Rules \& Gold. Journal of Maritime Law \& Commerce. January, 1995. 26 J. Mar. L. \& Com. 133. Obtenido el 31 de julio de 2016 de: http://www.lexisnexis. com.ezproxy.javeriana.edu.co:2048/hottopics/lnacademic/?

Yancey, B.W. (1982). Carriage of goods: Hague, Cogsa, Visby and Hamburg. Tulane Law Review Vol. 57 Issue 5. Pp. 1238-1259. Obtenido el 31 de Julio de 2016 de: http://heinonline.org.ezproxy.javeriana.edu.co:2048/HOL/Page?handle=hein journals/tulr57\&div $=41 \&$ start_page $=1238 \&$ collection $=$ journals\&set_as cursor $=0 \&$ men_tab $=$ srchresults 


\section{JURISPRUDENCIA}

Corocraft Ltd v Pan American Airways Inc. Court of Appeal. November 7, 1968[1969] 1 Q. Reino Unido.

Corte Suprema de Justicia. Sentencia del 17 de diciembre de 1902. Colombia.

Corte Suprema de Justicia, Sala de Casación Civil. Sentencia del 22 de enero de 1991. M.P Eduardo García Sarmiento. Colombia

Corte Suprema de Justicia. Sala de Casación Civil. Sentencia del 30 de septiembre de 2002. M.P. Carlos Ignacio Jaramillo Jaramillo. Colombia

Corte Suprema de Justicia, Sala de Casación Civil. Sentencia del 8 de septiembre de 2011. M.P. William Namen Vargas. Colombia

Corte Suprema de Justicia, Sala Civil. Sentencia del 21 de Julio de 2008. M. P. Harley James Mitchell D. Panamá

Corte Suprema de Justicia, Sala Civil. Sentencia del 27 de Julio de 2001, M. P. Rogelio A. Fábrega Z. Panamá

Cour d'Appel d'Aix-en-Provence, 2ème Chambre ARRÊT AU FOND DU 3 JUILLET 2008 No 2008/ 280 N$^{\circ}$ de RG: 07/09200. Francia

Cour d'Appel de Versailles, 12ème chambre section 2 D.C./P.G. ARRET N DU 31 mai 2001 R.G. N 98/04056. Francia.

Cour d'Appel de Versailles, 12ème chambre section 2 J.F.F. ARRET DU 02 Octobre 2003 R.G. N. 01/07128. Francia.

Cour d'Appel de Versailles, du 30 mars 2000, Nº de RG: 1997-3796. Francia

Court de Cassation, chambre commerciale. $\mathrm{N}^{\circ}$ de pourvoi: 14-24912. Francia

Cour de Cassation, chambre commerciale. $\mathrm{N}^{\circ}$ de pourvoi: 13-28846. Francia

Daewoo Heavy Industries Ltd \& Anr v. Klipriver Shipping Ltd \& Anr 20021554 A3 Court of Appeal (Civil Division). Reino Unido.

Fujitsu Computer Products Corp, Fujitsu Limited, Fujitsu Europe Limited v. B.AX Global Inc, Bax Global (UK) Limited, Bax Global Limited, Bax Global Limited, Bax Global Inc, Bax Global Inc Case No: 2003 Folio No 595 High Court of Justice Queen's Bench Division Commercial C. Reino Unido.

New York Court of Appeals. American Smelting \& Refining Co. V. Philippine Air Lines Inc [1954] U.S. \& Ca.Av.Rep. 221. Estados Unidos de América. 
Supreme Court of the United States. KAWASAKI KISEN KAISHA LTD. ET AL. v. REGAL- BELOIT CORP. ET AL. No. 08-1553. Estados Unidos de América.

Supreme Court of the United States. NORFOLK SOUTHERN RAILWAY CO. v. JAMES N. KIRBY, PTY LTD., DBA KIRBY ENGINEERING, ET AL. No. 02-1028.

Supreme Court of the United States. Trans World Airlines, Inc. v. Franklin Mint Corp. No. 82-1186.

Supreme Court of the United States. VIMAR SEGUROS Y REASEG. v. M/V SKY REEFER No. 94-623. Obtenido el 20 de junio de 2016 de: https://www.law. cornell.edu/supremecourt/text/515/528

Supremo Tribunal de Justicia. Recurso Especial No 1.076.465 - SP (2008/0160567-4) del 09.11.1994, Relator Ministro Marco Buzzi. Brasil

Supremo Tribunal de Justicia. Recurso Especial No 1.162.649 - SP (2009/0209202-1). Relator Ministro Luis Felipe Salomão. Brasil.

Supremo Tribunal de Justicia. Recurso Especial 39.082/SP. Relator Ministro Nilson Naves. Brasil.

Supremo Tribunal de Justicia. Rel. p/ Acórdão Ministro Fontes de Alencar, Segunda Seção, julgado em 09.11.1994, DJ 20.03.1995. Brasil.

The "Hollandia” (“Morviken”) (1983). Reino Unido.

The Chanda (1989) 2 Lloyds Rep 494. Reino Unido.

The Owners of the Ships or Vessels "Djatianom" et al v. The Owners of Cargo Lately Laden on the Ship or Vessel "Benarty" P.T. Djakarta Lloyd v. R.A. Lister and Company Limited and Others In the Supreme Court of Judicature Court of Appeal (Civil Division) On Appeal from an Order of Mr Justice Sheen 15 July 19841984 WL 988541. Reino Unido.

Tribunal de Justicia de Sao Paulo. Sentencia No. 2016.0000053634 de Enero de 2016. M.P. Edson Luiz de Queiroz. Brasil

Tribunal de Justicia de Sao Paulo. Sentencia No. 2015.0000901228. M.P. Marino Neto. Brasil

Tribunal Superior del Distrito Judicial de Bogotá. Sentencia del 11 de febrero de 1977. M.P. Hugo Vela Camelo. Colombia.

Tribunal Superior del Distrito de Bogotá. Sentencia del 28 de noviembre de 1984. Colombia.

Quantum Corp Ltd \& Ors v. Plane Trucking Ltd \& Anor. Queen's Bench Division (Commercial Court)10 April 2001. Reino Unido. 


\section{NORMATIVIDAD}

Código Civil Colombiano (CCC). Ley 57 de 1887. Colombia

Código de Comercio Colombiano (CC0). Decreto 471 de 1970. Colombia

Comunidad Andina de Naciones (CAN). Decisión 331 de 1993.

Comunidad Andina de Naciones (CAN). Decisión 397 de 1997.

Convención Internacional por la unificación de ciertas reglas en materia de conocimiento de embarque 25 de agosto de 1924. (Reglas de la Haya).

Convención Relativa al Contrato de Transporte Internacional de Mercaderías por Carretera (CMR).

Convenio de las Naciones Unidas sobre el Transporte Marítimo de Mercancías. Hamburgo, 1978.(Reglas de Hamburgo).

Convenio para la Unificación de Ciertas Reglas Relativas al Transporte Aéreo Internacional Firmado en Varsovia el 12 de octubre de 1929.

Convenio para la Unificación de ciertas reglas para el transporte Aéreo Internacional, hecho en Montreal el 28 de mayo de 1999.

Convenio de las Naciones Unidas sobre el Contrato de Transporte Internacional de Mercancías Total o Parcialmente Marítimo. Firmado el 23 de septiembre de 2009 en Rotterdam. (Reglas de Rotterdam).

Decreto 390 de 2016 (Ministerio de Hacienda y de Crédito Público). Por el cual se establece la regulación aduanera. 7 de marzo de 2016.

Ley 701 de 2001. Por medio de la cual se aprueba el "Convenio para la unificación de ciertas reglas para el transporte aéreo internacional” hecho en Montreal, el veintiocho (28) de mayo de mil novecientos noventa y nueve (1999). D.O. 44.628

Organización Aeronáutica Civil Internacional (OACI): Suplemento del 20 de abril de 2010 .

Protocolo para emendar el Convenio para la Unificación de Ciertas Reglas Relativas al Transporte Aéreo Internacional Firmado en Varsovia el 12 de octubre de 1929. 28 de Septiembre de 1955.

United States Code. (USC). United States of America. 